\title{
Research on Innovative Smart Home Design Based on User Experience
}

\author{
$\mathrm{Ze} \mathrm{Fu}{ }^{\mathrm{a},}$ * \\ Yiwu Industrial and Commercial College, Yiwu, 322000, China. \\ a, *447472145@qq.com
}

Keywords: User Experience; Smart Home; Product Design; Innovation.

\begin{abstract}
In recent years, with the progress of the society, a lot of intelligent products have appeared. These intelligent products are excellent in all aspects, and their performance is very satisfactory. The satisfaction degree is no less than the comfort, satisfaction, convenience and superiority of high quality artificial service. The original intention of intelligent products is multiple, but one thing is common, that is to say its original purpose is to make people gradually realize the convenience brought by the industrial revolution. We often say to improve the sense of experience of the people, to improve the sense of satisfaction of the people, to improve the sense of gain of the people, and to improve the sense of existence and happiness of the people in the present and contemporary developed society. The feeling of experience is a very mysterious word. People live in a society, and we are all one of them. Social relationship is a network connecting these very many points. We live happily on this website. Our social relationship with others is a line connecting these nodes. The premise that our society can work in an orderly way is that the net should be dense and compact. If each of us has a sense of experience and a good sense of experience, then this society can operate efficiently, and in turn, we can get more experience, which makes us more experienced and enrich our life. Then we can also say that the people have acquired a sense of happiness, a sense of satisfaction and a sense of experience, which is the good embodiment of the superiority of socialism and the concrete representation of the superiority of socialism. From the perspective of smart home, this paper aims at the experience of the people, and expounds the design of the smart home which meets the experience of the people. The survey shows that this combination is very promising and is what the general public wants.
\end{abstract}

\section{Introduction}

Since the emergence of an intelligent building in the United States in the 90s of last century [6], this building has aroused a great deal of response around the world. There are a lot of people who have questioned the fact that they are superficial, not practical, nor is it not practical for these seemingly perfect buildings [1], or, in some ways [2], that these buildings are not safe at all [7]. This has also caused people's panic to a certain extent [4], causing the general public to think about science and technology [3], but history is always astonishing [5]. Some one-sided statements do not block the development of society. On the contrary, it will only deepen our desire for deep technology [8].

As we all know, history is always moving forward, no matter how good or bad it is. The service industry has developed perfectly in an increasingly developed society [9]. It is good to say that the degree of development of a country depends on whether the service industry in this country is doing very well, and at the very least, it is as good as we imagined. After a lot of hard working people's experience, after many people's hard work, of course, of course, there is no lack of the support of the state, our products gradually to intelligent development. For such a satisfactory development, we cannot do without the efforts of everyone in our society. The development of any one aspect is no single, and its development is bound to pass through the development of a complete industrial chain and through the successive practice to reach the point of today. When it comes to intelligence, people always think of the word "Internet". Network TV, network TV, network air conditioning, network washing machine [10], network lamp and so on a series of intelligent products, a series of intelligent zed products which make us stunning. But this is not very correct. The answer is not perfect. The definition of intelligence is so extensive that we can briefly describe it as follows: a series of 
technologies, such as network communications, integrated wiring, network prevention, and so on, and the technology that combines these ideas with the various subsystems needed by the family through the home information management platform. The products are called smart home products [11].

At present, many companies already have foresight to invest in smart home research and development at great expense. To know, the behavior of these companies can be praised; their work has promoted the progress of the society to a certain extent and promoted the rapid development of the smart home. These companies are all over the world, such as HUAWEI, ZTE, millet, Apple Corp, or some small companies that are not famous. Their studies are all over the times and are very good. In this paper, based on user experience, we explain in detail the leading role of user experience in R \& $\mathrm{D}$ of smart home. These proposals and scheme design are more instructive for smart home. Here we come to introduce these ideas, and finally give our design, and believe that it is a strong impetus for the engineering application of smart home.

\section{Smart Homes}

In recent years, with the popularity of smart phones, smart home with smart phones as control platform, compared with the original smart home, it has a great advantage, not only so we have saved the trouble of wiring. We only need a simple action to make our home smarter, which is what we yearn for, and we are very eager to get. At present, many companies already have foresight to invest in smart home research and development at great expense [12].

At present, many companies already have foresight to invest in smart home research and development at great expense. To know, the behavior of these companies can be praised, their work has promoted the progress of the society to a certain extent and promoted the rapid development of the smart home. These companies are all over the world, such as HUAWEI, ZTE, millet, Apple Corp, or some small companies that are not famous. Their studies are all over the times and are very good. In this paper, based on user experience, we explain in detail the leading role of user experience in R \& $\mathrm{D}$ of smart home. These proposals and scheme design are more instructive for smart home. Here we come to introduce these ideas, and finally give our design, and believe that it is a strong impetus for the engineering application of smart home [13].

When we use some products, it is inevitable that the first time we think of the safety problem of this product design, in this respect, the smart home can be completely reassuring users [14]. No matter how well the hardware facilities and personnel management are in place, we must have the heart to observe the safety problem. This is very necessary. The occurrence of some emergencies in life is not a few, once it happens, we have to have enough energy and common sense to deal with it, otherwise the consequences will be unthinkable [15].

The object of the smart home is that we - the ordinary people, so it is not what we want, even if it is easy to be more intelligent, even if it is out of the user's smart home. Moreover, we hope it can be more innovative because innovation is the source of social development and provides an inexhaustible motive force for social productivity. Based on this, we propose a scheme of smart home design based on user experience. At the core of the user, it is convenient for the user [16].

\section{Design Based on Experience}

As mentioned above, in order to improve the sense of user experience, we are designed to facilitate the user's starting point, detailed consideration of the various problems that the user may encounter in life.

The feeling of experience is a very mysterious word. People live in a society, and we are all one of them. Social relationship is a network connecting these very many points. We live happily on this website. Our social relationship with others is a line connecting these nodes. The premise that our society can work in an orderly way is that the net should be dense and compact. If each of us has a sense of experience and a good sense of experience, then this society can operate efficiently, and in 
turn, we can get more experience, which makes us more experienced and enrich our life. Then we can also say that the people have acquired a sense of happiness, a sense of satisfaction and a sense of experience, which is the good embodiment of the superiority of socialism and the concrete representation of the superiority of socialism. From the perspective of smart home, this paper aims at the experience of the people, and expounds the design of the smart home which meets the experience of the people. The survey shows that this combination is very promising and is what the general public wants.

For example, the owners go out, no one in the home, at this time the air conditioning, fan and other electrical appliances are closed, but the door control system works; when households go home, start home scenario model (as shown in the following chart). The first thing the household needs to do is to brush the RFID card, if not given the authority, then the system does not perform any operation; otherwise the entrance guard system will open automatically and turn on the TV. We can also set up our own security mode [17], student mode and child mode to protect every member in your family. The detailed schematic diagram is as follows. We will not repeat it here.

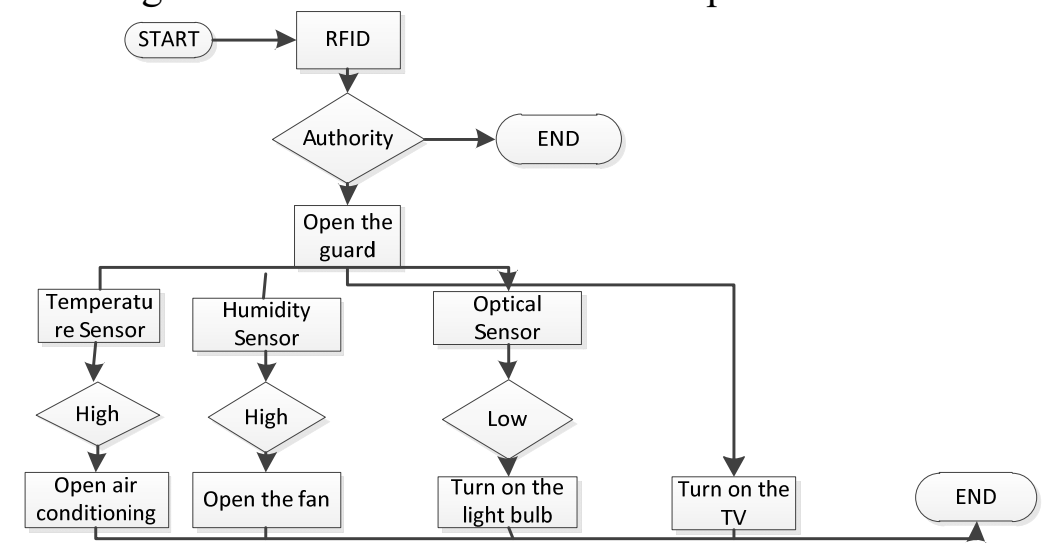

Figure 1. General Processes

\section{Conclusion}

So far, smart home has experienced nearly 12 years of development in China, and it has been serving us all the time in the past 12 years [19]. From people's original dream to today's real life, we can say that all these things are exciting for people. In the progress of the people's home concept is also constantly improving, we all yearn for a more comfortable and safer modern home, because these will greatly improve our life. But at the same time, we should also pay more attention to the improvement of people's sense of experience [18], because for a technology, if it is contrary to the sense of comfort, it is meaningless, or unnecessary, is unnecessary. In this paper, we propose a design of smart home based on experience, which has many conveniences. But it is by no means the most perfect, because the most perfect design is always in the future, and we will also face the future with eager attitude.

\section{Acknowledgments}

2017 Zhejiang Provincial Department of Education General Questions (Y201737448).

\section{References}

[1]. Japanese Company Developed New-type of Textiles: Monitoring Hate Rate for Users [J]. Shanghai Textile Science\&Technology,2013(8):63.

[2]. O'Mahony Advanced Textiles for Health and Well-Being [M]. New York: Thames Hudson, 2011. 
[3]. Howes P, Laughlin Material Matters: New Materials in Design[M]. London: Black Dog Puhlishing,2012.

[4]. Quinn Textile Futures: Fashion, Design and Technology [M]. London: Blooms boy Academic, 2010.

[5]. Chen Jan-Ii. Development and Application of Smart Textile and Garment[C].2013 Shanghai Textile Clothing of Creative Innovation Foremother Seventh China Textile and Apparel Innovation International Forum, 2014:96-99.

[6]. Chen Mao-churns N Wei, ZHAO Xiao-hut. Human-Computer Interaction in Internet of Things Smart Home [J]. Packaging Engineering, 2014, 35(2):64-7.

[7]. Zhang Zhan-long, LI Haying. Study on the Impacts of Inter-net of Things Era on Industrial Design [J]. Packaging Engineering,2011,32(14):122-125.

[8]. Liu Gangue. Developing Direction and New Technology of Smart Home[J]. Computer CD Software and Applications, 2012(1):64-65.

[9]. Amble, T. The social psychology of creativity's componential conceptualization, Journal of Personality and Social Psychology [M]. 1983, T 45:357-376.

[10]. De Silva R, Dutra M J, et al. Personal identity module using psych evolutionary emotion theory for social robots [J]. 2012 IEEE ROMAN: The 21st IEEE International Symposium on Robot and Human Interactive Communication. September 9-13, 2012. Paris, France: 551-557.

[11]. Beale R, Creed Affective Interaction: How Emotional Agents Affect Users [J]. International Journal Human Computer Studies, 2009, 67(9):121-123.

[12]. Lanfranc M, Le Gars D. Robotic implantation of deep infra-operative flat-panel CT [J]. Act Neurotic (alien). 2012 brain stimulation leads assisted by,154 (11):2069-2074.

[13]. Amble, T. The social psychology of creativity's componential conceptualization, Journal of Personality and Social Psychology [M]. 1983, T 45:357-376.

[14]. De Silva R, Dutra M J, et al. Personal identity module using psych evolutionary emotion theory for social robots [J]. 2012 IEEE ROMAN: The 21st IEEE International Symposium on Robot and Human Interactive Communication. September 9-13, 2012. Paris, France: 551-557.

[15]. Van Linen P H G, Wijngaards N J E, Brazier F M T. towards designing creative artificial systems, Artificial Intelligence for Engineering Design, Analysis and Manufacturing [J]. 2004, 18(3):217-225.

[16]. Kim H R, Kwon D Computational Model of Emotion Generation for Human-Robot Interaction Based on the Cognitive Appraisal Theory[J]. Journal of Intelligent \& Robotics Systems, $2010,60(2): 78-80$.

[17]. Hyun K H, Kim E H, Kwak Y Emotional Feature Extraction Method Based on the Concentration of Phoneme Influence for Human-Robot Interaction[J]. Advanced Robotics, 2010, 24(1-2):33-35.

[18]. Xiao Ran, LI Shi-gun, Pan Zoos-ping. The Application of Interaction Design in the Product Application of Feed-forward Mechanism [J]. Packaging Engineering, 2010, 31(18):31-34.

[19]. Hyun K H, Kim E H, Kwak Y Emotional Feature Extraction Method Based on the Concentration of Phoneme Influence for Human-Robot Interaction[J]. Advanced Robotics, 2010, 24(1-2):33-35. 